\author{
MAEGORZATA A. SZYSZKOWSKA ${ }^{1}$ \\ https://orcid.org/0000-0003-1783-256X \\ Fryderyk Chopin University of Music
}

\title{
Narrative moment. Musical performance according to Lawrence Kramer and James Baldwin
}

\begin{abstract}
My aims are to investigate how the concept of narrative moment may be helpful in capturing the role of music in creating profound communication on the level of performing as well as listening to musical performance. I aim to show how sharing a culminating moment in a musical experience may lead to inducing a state of self-awareness and confidence in place of critical separation and distrust.

I discuss Lawrence Kramer's idea of the narrative moment explained in original in reference to a literary example and an improvised music. It is presented as an example of communicative potential in music performance, which as I argue, is worth exploring and explaining further. Suggesting a possibility of narrative moment in the experience of musical performances offers a comprehensible and applicable vision of communicative potential of music that is far reaching even if rarely achieved; a possibility of communication that is direct and intuitive, flexible and affective.

Defining musical meaning in terms of its music's communicative power and far reaching social consequences suggests deep connections between the social/intersubjective, individual/subjective and aesthetic aspects of life. The proper explanation of the meaning of music requires drawing from different domains, including metaphors and highly persuasive literary and musical examples.
\end{abstract}

KEYWORDS: narrative moment, music, aesthetic experience, improvisation, communication

\section{Introduction}

All I know about music, is that not many people really hear it (Baldwin, 2009, p. 45)

The aim of this paper is to present narrative moment, a concept Lawrence Kramer (b. 1946) introduced in his article under the same title in 1999. Kramer used this concept as a valid aesthetic category and an analytical tool.

\footnotetext{
${ }^{1}$ Work created as a result of research project no. 2016/23/B/HS1/02325 financed by the National Science Center.
} 
Yet, the concept of narrative moment has not made it into the circle of the appreciated ideas in aesthetics. But perhaps it should. It is useful for discussing the meaning in and of the music. In what follows I would like to suggest that the concept used by Kramer is in fact a great aesthetic tool. It shows how narrativity - sharing stories, also musical stories - may function as a remedy for pain and grief. It shows how experiencing musical epiphany may at the same time function as a therapeutic and inducive impulse. It shows that sharing a story through music is meaningful in far more important ways than previously expected.

My aims are to investigate how the concept of narrative moment may be helpful in capturing the role of music in creating profound communication on the level of performing as well as listening to musical performance. How sharing a culminating moment in a musical experience may lead to inducing a state of self-awareness and confidence in place of critical separation and distrust. I intend at least to try to show how the narrative moment might be regarded as the moment of personal truth and self-discovery in times of trouble and pain relying on Lawrence Kramer's examples and my own suggestions of musical performative experiences.

In any performative artistic situation there might come a moment of reaching full communicative potential, arriving at the best possible 'place', where all that was imagined has been realized artistically and for anyone listening it becomes a moment of communal truth, of finding a common sense - literally a meaning everyone seems to understand. But such cumulative, crowning moments are brief and passing, and they do not always happen when expected. The concept of narrative moment seems to capture perfectly the fleeting and short and yet extremely important time during a performance, which attests to its worth.

Especially in music, devoid of linguistic meaning unless it is accompanied by text or explicit markings suggestive of words or images (Kramer, 1995, p. 99), the fact that it can still carry shared meaning and communicative fulfilment, needs some explaining. I am sure, nonetheless, that even if the 'telling story' imperative in jazz music, as Vijay Iyer calls, is perhaps less than ascertained (Iyer, 2004, p. 393), it makes perfect sense to talk about narrative moment in music at least in the sense sketched above.

\section{The narrative moment}

Kramer begins his paper acknowledging a 'connection between music and a certain kind of story-telling' that is both personal and communal. His example, which I would like to retain, is James Baldwin's (1924-1987) classic short story Sonny's Blues, in which jazz music is used for suggesting a possibility of healing in re-telling of deepest truth and where the name blues - as in fact in many other examples of film or fiction - is used as a metaphor for something that is personal, subjective and yet communal even if this understanding of blues is at the same time somehow contested (Sherard, 1998, p. 693). The narrative Baldwin weaves is ironic and suitably undermining its own surface meanings. It is a story about telling stories. As blues and the stories people tell and long to 
share with others by way of blues, might no longer be possible, the author introduces jazz (bebop) as more appropriate even if hermetic narrative that would stand in for storytelling and the power behind it (Sherard, 1998, p. 694).

In art as well as life, according to Lawrence Kramer, there is a possibility of reaching a powerful moment revealing a unique state of being in tune with oneself and the world, the feeling or belief of 'seeing clearly', of 'understanding', despite changing conditions and doubtful attitudes Kramer points to Bobby McFerrin's improvised Circlesongs project as presenting performance, through which listeners and singers achieve deep common understanding, a climactic narrative moment. I would like to present this idea further suggesting that what Kramer's saw and heard in McFerrin's performance is present in many musical performances, improvised or otherwise and therefore his idea - the narrative moment - may be seen as a truly helpful aesthetic tool.

Before I can explain what I mean by that, let me briefly come back to James Baldwin's literary account of musical performance, which is as challenging as it is captivating.

\section{Music in the story}

Baldwin's short story Sonny's Blues is about music (blues) and about pain (blues) which sets the ambience for the story about forgiveness, remembering, getting away and coming back; the story about courage to be who you are and a necessity to trust in common experience. And so much more, obviously. It is also the story about music's ability to provide means for communication, understanding and self-realization - both truly and falsely.

The story the music is playing and telling appears towards the very end - it is the kind of telling that changes people, helping them accept their own communal and individual self. But I do believe that Baldwin brings to our attention more than blues and jazz and more than the sound of any music. He presents to us the music residing inside of man, awaken with the sounds of particular experiences, the very ground for listening, the base for communication, the memory that allows for recognition of self. The music which allows for bonding within community not because of its strength but despite its weakness, in other words - the music as humanly experienced, as sounding and re-sounding back.

Music appears first in the story as backdrop for telling stories, or a metaphor for a narrative, a story but also an attempt to be heard, to be listened to, to be noticed. But it is also, finally, a main character of the short story as the musical concert through which listeners are touched and their lives are changed. Music is presented here as a vehicle for installing meaning and restoring balance.

\section{The story}

Sonny's Blues is a story about expectations and assumptions, about inability to express oneself and a strong need to do so. When the story begins the 
protagonist has just learnt about his brother being arrested with shock and disappointment. But as we gradually learn his disappointment is not only with his younger brother but with himself. As much as he is trying to disassociate himself with the community's problems, he also remembers his family and the story that haunts him personally. In the end it is only through the experience of listening to his brother's piano playing, through the story told by the music in Baldwin's words, that the main character is able to realize the truth, his being part of the community and his unbreakable bond with his younger brother. In the end the value of music as providing genuine experience - the experience of shared history and self-recognition - becomes recognized.

Tracey Sherard in her work on Baldwin suggests that Sonny's Blues is a blueprint for storytelling. Sonny's Blues not only tells a story; it is about the telling of stories (Sherard, 1998, p. 692). All spheres of life are recognized as stories to be told. The words suggesting telling and listening to a story, implying things to be shared or hidden from view, abound in the text. There is also the suggestion that people have something both painful and meaningful about themselves - in way of their lifepath, their experiences, their struggles - that they want and need to share. It is this sharing, silent at times or even only assumed, that makes a community what it is. But to be a part of such a community, one must realize and understand the possibility of sharing, the similiarities, the limitations. In Baldwin's short story Sonny's brother as narrator is also the storyteller: he remembers stories about his brother and himself and he tells these stories, refining parts of them, trying to understand his life and the lives of others through them. But, as he realizes, everyone has a story to tell, and everyone's story is most important to them. 'I felt guilty-guilty, probably, for never having supposed that the poor bastard had a story of his own' (Baldwin, 2009, p. 20).

What exactly is a story then, one might ask. I would like to propose that a story is something, that has meaning and something, that may be told or expressed as having meaning. This broad understanding of a story is perhaps too generous, but as one notices, a story pops up in many places as far away from the literary or poetic discourse as possible. And music is just one of those places. It seems a perfect vehicle for telling a story, despite the fact that this telling may be as difficult to decipher as it is to do.

In Baldwin's short story, as the main character realizes, it is all about having a story to tell and about molding life experiences into one. So the life itself and the hardships one faces, become the story. But as much as thinking about it helps the main character, it is only through the experience of music, through realizing that someone else - Sonny - is telling his story and that this story is more than personal, the main character is finally reconciled with the community. He finally understands the difficulty and pain behind the process of forging a community, the musical and social process of sharing and he is able to imagine the choices and deep emotions Sonny has to face.

Perhaps, I should revise my definition of the story. The story may be seen as the experiences that are expressed and thus shared. Although no one really knows, what are the experiences or feelings behind the story (Levinson, 1995, p. 185). 
We recognize the story as the human experience both imagined and real. And acknowledging the effort in sharing, in telling the story, means that the performance is successful. But it is more than that. The story itself functions as a process of recognition. As the main character in Baldwin's text realizes his family's pain and later on the possibility of accepting his own path, so the reader learns the process of storytelling and recognizes its main elements.

\section{Truth in music}

The truth in art presents an immanent problem. What could possibly be true about art when art is by definition based on fictional or imaginative creation and as such it should not be judged in reference to the flawed. Yet in art truth becomes most important. It is the untrue art that seems flawed or even invalid. What is true art, then? Perhaps art that is brought from hiding into the light, or maybe the art that is most felt through? In such cases art most expressive in presentation would be considered the most true. However, the most expressive performance might not always be the most felt through. A Heidegger's concept of truth as unhidden (aletheia) points to the other element of truth in art, the visibility of being, making something visible or such, that everyone will talk about it (Heidegger, 2004, p. 42). In case of music, it is the condition of being heard.

Music must be heard - says one of the characters in Baldwin's story. It means that there must be those who will listen to it. As Creole says this to Sonny, we might infer that if someone wants to play music or jazz more specifically, it must be played in such a way as to make everyone listen. So on the one hand we have prerequisite of performative expressive skills for music experience. Music requires the skill of delivering a powerful and overwhelming performance. But on the other hand it might be said that Baldwin shows music to be like truth. It must be heard, it demands attention. It is perhaps why the main character says somewhere in the story 'all I know about music is that not many people really hear it' (Baldwin, 2009, p. 45). It is also during listening to the band's music performance that Sonny's brother understands that Sonny is truly able to tell the story. And the story, he tells, is as true as anything he himself remembers or tries to forget. Music must be heard in the sense that it delivers the possibility for engagement and, with it, the ability to understand one another. It is not just the music - one might say - but the embodiment, the bodily effort, the truth understood through the feeling and struggle in the performance. Sonny's blues require not only skills in terms of ability to play the instrument, but more importantly, in providing a truly moving performance, such that can only be achieved if the inner truth is being exposed and shared through the music. As when the musician is ready to be listened to. Music that is true in uncovering the inner self and its story. Music, and through it the experience of listening to music, becomes truth, which must be recognized and dealt with. In the end, it becomes a tool for recognition and self-realization. 


\section{Musical experience}

In James Baldwin's story the protagonist's realization and the acceptance of his brother's music with its deep collective meaning, and, more importantly, his own place in the community and the truth about his feelings becomes possible through the experience of music. Music is being used as narrative material but its narrativity is performative. The performance Sonny's brother is watching tells him more about his brother than all their previous conversations. $\mathrm{He}$ is able to grasp the deep engagement and bodily passion that underlies the music. He is able to hear the music as the personal story and in this he hears his brother as well. The performance is a means to reaching out to others and making them part of the community. In the roaring darkness of life - as Baldwin suggests - music provides the light (Baldwin, 2009, p. 20).

Music is performative, in this that it requires touching, engaging, joining in. It provides real life experience that is at the same time reflective and performative. The listeners, if they are really listening, are joining in the music, swinging, whistling, singing or taping along. Few references to music that we can trace in Sonny's Blues are all about the way how someone's voice sounds or how music highlights the atmosphere making the situation evidently more sad or childlike or desperate. Music is always revealing something deep in the way it sounds, in the way it is performed. It is presented through someone's performance and therefore as well through an experience. Music is an experience. Thus the phenomenological quality of music is both in its performance and in the way it is received. Both are one.

In Baldwin's story music provides means to escape from the hopeless life - metaphorical darkness - as well as to create freedom, metaphorical light (Baldwin, 2009, p. 47). Towards the end of the story music is portrayed again through an experience. The experience, in which the main character is able to hear the music. In his subjective, attentive, painful and revealing experience we learn about the music he listens to. Music as an artistic expression, expressive and transformative, provides a way of coping with suffering and longing; inviting the listener to step into the subjective realm of feelings. In Baldwin's story it is presented as a set of dialogues, a dispute, a close exchange of voices, of skills, of artistic gestures and musical material. Music becomes truth - it demands listening while at the same time provides a unique yet common story to be heard. And Sonny's brother is able to hear it.

And, while Creole listened, Sonny moved, deep within, exactly like someone in torment. [...] Something began to happen. [...] The dry, low, black man said something awful on the drums, Creole answered, and the drums talked back. Then the horn insisted, sweet and high, slightly detached perhaps, and Creole listened, commenting now and then, dry, and driving [...] (Baldwin, 2009, p. 46).

Creole began to tell us what the blues were all about. They were not about anything very new. $\mathrm{He}$ and his boys up there were keeping it new, at the risk of ruin, destruction, madness, and death, in order to find new ways to make us listen. For, while the tale of how we suffer, and how we are delighted, and how we may triumph is never new, it always must be heard (Baldwin, 2009, p. 47). 


\section{Narrative moment?}

According to Lawrence Kramer narrative moment is a time when music's narrative builds upon itself reaching a culmination. Narrative moment is this climax of musical experience, through which certain deeper understanding may be reached and shared. Which understanding or understanding of what, we do not know. Whatever discovery is being made, be it on the level of music itself, the level of sound or timbre, or the level of psychological truth, will be different for everyone. Still the sense of communion, the shared experience comes with the feeling of togetherness simply because in one place and time a group of listeners is responding in a similar way to one and the same - again in a simplified sense relative to objectified time - musical performance.

In his text Kramer provides model for the narrative moment in music. A model supplemented with excerpts from Baldwin's short story, where reaching to the deep and difficult truth is being portrayed (Kramer, 1999, p. 60). Kramer's model displays four phases leading up to and resulting in 'capturing a story in [Sonny's] music' (Kramer, 1999, p. 60). Here is my recapitulation of that model together with appropriate citations.

(1) Phase one is a warm-up, trial and error, emotionally tentative.

(2) Phase two is a dialogue, an exchange of musical ideas by the players, call and response: 'Something began to happen [...] The dry, low, black man said something awful on the drums. Creole answered, and the drums talked back. Then the horn insisted, sweet and high, slight'.

(3) Phase three 'turns the aesthetic pleasure generated by phase two into an expressive challenge; it returns the music to its roots in experience. «Creole stepped forward to remind them that what they were playing was the blues [...] the tale of how we suffer, and how we are delighted, and how we may triumph»' quoted after Kramer (1999, pp. 59-60).

(4) Phase four 'a soloist steps forth and captures the story in his music' (Kramer, 1999, p. 60).

Trying to grasp the exact meaning of the narrative moment one might consider that apart from the process sketched above by Kramer (in which accumulation of artistic processes leads to a culmination point) the narrative moment includes various aesthetic aspects that need to be acknowledged as well. Perhaps there is more at stake here and more needs to be done to reach the narrative moment that this schematic presentation implies. When playing and singing together, musicians relay on each other, and they also heavily influence each other, yet it rarely happens that such shared performance results in a narrative moment, a moment of clarity and expressive power, great achievement and qualitative richness. There are however moments, in which the quality of performance, as well as the structure of a musical piece come together so potent and well played and the music simply speaks volumes. Still, as Vijay Iyer (2004) suggests, those musical exchanges are extremely complex and even more perplexing especially in the context of jazz music. Iyer explains the possible character of jazz impro- 
visation as at the same time avoiding telling stories and producing a new story in its harmonic structure through employing various (and unexpected) changes. In such situations musicians focus on the challenges with which they are presented as they play, but they also respond to the expressive nuances in the way of performance. They have to pay attention to the sound, the timbre, the details in expressive character of the solos. During these musical exchanges musicians are looking for some kind of sound or some kind of ambience to direct them, to drive them further and to suggest the climacting points.

In Baldwin's description such details are absent as the players are trying to express the deepest, most difficult feelings rather than to find new ways of playing. They struggle with pain that tires them down. Their struggle is in telling the story, which is not just their own, but everyone else's. It is the communal story, the story of suffering, anger and despair. The way Baldwin portrays the jazz narrative is through presenting it as a spoken narrative - a quasi-verbal exchange ('...black man said something awful on the drums...'). In this exchange the telling is as important as listening, and hearing (true hearing), is this which enables understanding. And it is this understanding that may bring calmness and return one to life.

In his text Kramer introduces improvised music, which seems to him paradigmatic in providing the climactic narrative moment. He talks about Bobby McFerrin series of concerts with Voicestra ensemble. According to him it provides an excellent example of driving for and achieving the narrative moment (Kramer, 1999, p. 60). Let me quote a little bit from Kramer's description of McFerrin's performance.

After some time, a solo female voice quite suddenly emerges high above the ensemble and begins a vocalize [...]. McFerrin responds to this gesture by stopping the ensemble and letting the voice continue alone. His decision seems spontaneous, and I believe it can be said to constitute his recognition and reception of the narrative moment. The sudden gleam of the high female voice, ...marks the end of meandering; [...] It tells the story of the group by being recognized as the goal of the search process (Kramer, 1999, p. 61, emphasis MS).

According to McFerrin the Circlesong project was about employing a search process, unpredictable and full of meandering, for which, as Kramer suggests, the ultimate goal was an 'emotional and social truth' (Kramer, 1999, p. 60). This truth, which may be known in general terms (e.g. in terms of music harmonic expectations), in its concrete manifestation remains 'unknown until it breaks through' (Kramer, 1999, p. 60). Voicestra's improvised music provides a way of unifying both performers and listeners, allowing them to experience the music making. The music creation employed is fairly simple, relying on repetitions and easy harmonizing, yet throughout the process it seems to reach the highest level of personal fulfillment and communal sharing thus providing an excellent example of true music making.

I find Kramer's example of Bobby McFerrin and Voicestra's concert even more persuasive and exemplary of narrative moment than the jazz concert imagined by Baldwin in his story. But I also believe that many more musical performances might offer such narrative moment to performers and listeners, provided they do listen. 


\section{Improvised music}

As Kramer suggests with his example, it is in jazz improvisation, the audiences and musicians alike aspire to and enjoy achieving climax and they participate in the dialoguing exchange of voices and 'stories'. The jazz performances usually feature the u-like shaped structure with climacting instrumental or vocal solo, that audiences appreciate so much. But in order for such a performance to be seen as including a narrative moment there must be more than an expression and skillful display. There must be a reference back to the music's communal power or the band's experience of sharing that at least musicians are able to recognize. However, as some musicians have underlined, the requirement of telling story, might be as vague as it is general.

Vijay Iyer, to whose music and works I would like to turn now, points out that contemporary musicians are tired of the constant suggestion of telling the story, whereas the musicologist rarely have analytical tools at their disposal to grasp the nuances involved in the complex ways of jazz music's narration (Iyer, 2004, p. 394). Perhaps, their way of realizing this postulate is more in the free and spontaneous musicianship than in attempting to show something to the audience. Or maybe, what Iyer is evidently irritated by will be achieved only through a communal effort. A problem with 'telling a story' might be that the idiom, one's music is contingent upon is no longer satisfactory. Every new and brave edition or change will be a new and different story (Iyer, 2004, p. 394). As author suggests, not telling the story already is a story that is being told (Iyer, 2004, p. 394). As much everything in jazz music - and in improvised music - relies on dialogue and reworking of possibilities, the struggle to change expectations or style is certainly received as a particular story. But there is much more Iyer suggests, that interpreters might want to analyze. All the small details, and subtle changes in the flow of the music, 'negotiating the harmonic maze' or 'displaying a strong personal timbre' or the inherent (bodily) structure of the performative itself might function as aggressive self-presentation or tell a story (Iyer, 2004, pp. 394-345). But such that the history and self-identification of more than the musical style will be at stake during such instrumental exchanges.

The sense of community is such that one only knows what might be at its heart if one spends a lot of time in the community. Wanting to be part of it or afraid to lose place in it. The climacting way of performing and understanding music in jazz or other genres, brings with it the idea of community and ability to share a moment as well a whole hour or two. Perhaps the narrative moment that Kramer proposed in his text is truly a moment of unified efforts in bringing a wonderful performance and however we want to understand the narrativity behind it always will be only clear to in that sense of feeling attached or wanting to hear more. There is no other sense of music narrativity. It is all in the process, in the dialogue and in sharing. The example I would like to end with is an example of another Bobby McFerrin's performance, which may be seen on YouTube. ${ }^{2}$

${ }^{2}$ See https://www.youtube.com/watch?v=WodODxpTbpA (accessed: 15.10.2018). 
During this performance a guest joins Bobby McFerrin in singing, as it often happens during his concerts. This particular guest was a part of Voicestra and is a music teacher. And in this performance, one may see a perfect cooperation between singers. An effort to help achieve the best results on part of McFerrin and an effort to be the best singer on part of the guest. As both performers reach their climax and are joined in recognition of their artistic success - this realization brings forward the narrative moment - communication and expression in performance, which realizes the truth of art. What is perhaps special about this performance, but which reflects on the way such shared experienced are to be conducted, is the constant back and forth exchange of places, accents and focuses. There is no equality in the way the music is sung or performative energies are distributed - there could not be. But there is a constant effort in sharing and providing space and possibility of voicing out to the other. And it is this, the narrative moment achieved, that is more than the moment of artistic success or even the revelation of the truth within. It is the example of sharing in its best; when one gives something away or withdraws to let the other person shine giving the best performance they are capable of.

\section{Musical meaning and telling of the story}

In Heidegger's explication of aletheia as the truth, the unhidden, it relies on seeing and understanding. The truth is making something explicit bringing it to light. In music the meaning or sense comes to light not because of the story but as a story, as telling of the story. Nothing, as Ihde explains, 'is shown through the music. The music presents itself; it is a dense embodied presence' (Ihde, 2007, p. 155). With this presence - performative expressive presence of the music - the meaning of music may be grasped but not as something that will be put into words or explained in any other way. The meaning of music in telling of the story is in sharing, in making it heard.

\section{Conclusions}

The concept of narrative moment introduced by Kramer seems to be a perfect aesthetic tool not just for music aesthetics but for aesthetics as such, as well. It is useful to highlight the moment, when art becomes communication, the moment of dialogue and communal sharing that art is supposed to allow for. Perhaps not all art reaches this potential, not all art may be seen as necessarily going in this direction. Some art truly and wonderfully is absolutely selfsufficient and about itself. But when it does happen, as it is often the case, art may be a perfect tool for communication, for enabling growing and for inspiring people in their actions. In Kramer's text we see that music finds within itself the moment of culmination, moment of truth and the revealing unifying point of junction. In this, the process of experiencing becomes unified, harmonious and 
the qualitative and multilayered character of music comes to the fore delivering satisfaction and feeling of aesthetic fulfilment.

Not necessarily due to its assumed narrativity, music as experienced, allows for forming of communal, shared space, in which the listeners may feel united, together, despite the actual individual and subjective character of their experiences. They think of themselves as part of the greater whole, their feed of each other just like the musicians do throughout their playing.

As much as the concept of narrative moment seems sketchy, or at least not fully explained by the author, is seems perfectly capable of describing the most important moment or moments of musical performance, socially, communally and artistically.

Perhaps, the narrative moment is a moment indeed, a culmination, which points not so much to the narrative character of music, or its ability to tell a story, but to music's ability to allow listeners and performers to be joined in a community. Music as vehicle allows for changing the perspective. The listeners, if they let themselves be carried by the music, feel the union of purpose, that seem to be both the reason for and the consequence of musical performance. In this achieved unity and in this persuasiveness of performed music lies a heart of the music. The moment of union, of belonging, of being one with community, of reaching the truth, both imagined and experienced. The moment of self-truth and coming together - the moment of understanding and re-instating the meaning of life, the narrative moment.

Let me close with Bobby McFerrin's words from his song Say Ladeo:

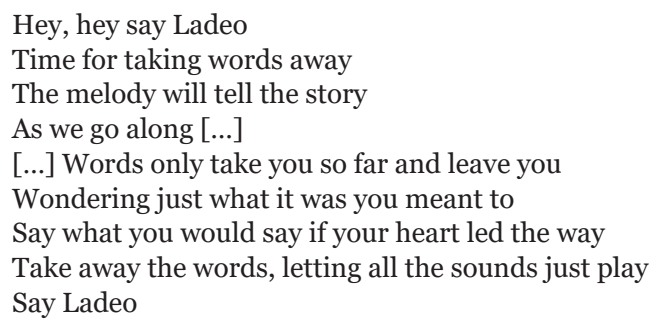

\section{References}

Baldwin, J. (2009). Bloomington: Indiana University Press. Sonny's Blues. In S. Feinstein, D. Rife (Eds.). The Jazz Fiction Anthology (pp. 17-38).

Bernstein, S. G. (1974). James Baldwin 'Sonny's Blues': A Message in Music. Negro American Literature Forum, 8(3): 231-233.

DeNora, T., \& Ansdell, G. (2014). What Can't Music Do?. Psychology of Well-Being: Theory, Research and Practice, 4(23): 1-10.

Ellison, R. W. (1995). Invisible Man. New York: Vintage Books.

Ellison, R. W. (2002). Living with the Music. Ralph Ellison's Jazz Writings, R. G. O'Meally (Ed.). New York: The Modern Library.

Golden, T. J. (2012). Epistemic Addiction: Reading 'Sonny's Blues' with Levinas, Kierkegaard, and Nietzsche. The Journal of Speculative Philosophy, 26(3): 554-571. 
Ihde, D. (2007). Listening and Voice. The Phenomenologies of Sound. Albany: State University of New York Press.

Iyer, V. (2004). Exploding the Narrative in Jazz Improvisation. In R. G. O'Meally, B. Hayes Edwards, F. J. Griffin (Eds.). Uptown Conversation: The New Jazz Studies (pp. 393-403). New York: Columbia University Press.

Iyer, V. (2006). Unlocking the Groove: Rhythm, Meter, and Musical Design in Electronic Dance Music. Journal of the Society of American Music, 2(02): 269-276.

Kramer L. (1995). Classical Music and Postmodern Knowledge. Berkeley: University of California Press.

Kramer, L. (1999). The Narrative Moment. Lenox Avenue: A Journal of Interarts Inquiry, 5: 59-62.

Kramer, L. (2002). Musical Meaning. Towards a Critical History. Berkeley: University of California Press.

Kramer, L. (2003). Musicology and Meaning. The Musical Times, 144(1883): 6-12.

Kramer, L. (2007). Why Classical Music Still Matters?. Berkeley: University of California Press.

Levinson, J. (1995). Messages in Art. Australasian Journal of Philosophy, 73(2): 184-198.

Jones, L. (1995). Blues People. The Negro Experience in America and the Music that Developed from it. New York: Payback Press.

Reilly, J. M. (1970). 'Sonny’s Blues': James Baldwin's Image of Black Community. Negro American Literature Forum, 4(2): 56-60.

Sherard, T. (1998). Sonny's Bebop: Baldwin's 'Blues Text' as Intracultural Critique. African American Review, 32(4): 691-702.

Szyszkowska, M. A. (2017). Wstuchując się $w$ muzykę. Studium z fenomenologii stuchania [Listening into music. A study in the phenomenology of listening]. Warszawa: Wydawnictwo Naukowe Semper.

Szyszkowska, M. A. (2018). Musical Phenomenology: Artistic Traditions and Everyday Experience. Avant, 9(2): 141-155.

Szyszkowska, M. A. (2010). Messages in Art And Music: On Route to Understanding Music Works with Jerrold Levinson. Dialogue and Universalism, 3-4: 98-106.

Music examples:

Bobby McFerrin and Voicestra in concert on YouTube: https://www.youtube.com/ watch?v=eitUBSoUxXY (Sessions on West 54th, part 2/3 - accessed: 15.10.2018).

https://www.youtube.com/watch?v=eitUBSoUxXY (accessed: 15.10.2018). 